\title{
Inbreeding of tiger (Panthera tigris tigris) in Nepal : a review
}

\author{
Tanka P. Acharya ${ }^{1}$
}

\begin{abstract}
Due to the continuous habitat destruction and fragmentation, the population of tiger is being restricted to smaller habitats. There is a lack of migration between the insular populations. The lack of gene flow in the isolated populations and, the decreasing size of populations in a given habitat, the probability of inbreeding and inbreeding depression have greatly increased in Nepal. The purpose of this paper is to study the probability of inbreeding depression in tiger in Nepal, and assess the efforts made so far to improve the situation.
\end{abstract}

Keywords : Panthera tigris tigris, inbreeding, inbreeding depression, Nepal.

T he tiger (Panthera tigris tigris) is one of the eight sub-species which once occurred in the Caspian and Southeast Siberia. It is popularly known as the "Royal Bengal Tiger" in Nepal, India, and Bangladesh. Due to poaching for trophies, bones and skin coupled with habitat degradation and isolation, the tiger population is declining at a fast rate. In 1969, the International Union for the Conservation of Nature (IUCN) listed it in the Red Data Book as an endangered species. There has been a systematic decline of tigers from an estimated 40,000 in the Indian sub-continent at the turn of the century to approximately 3,000 (Holloway et al. 1976). The majority of the population is found in India, and the rest are in Nepal, Bangladesh, Bhutan and Myanmar.

Isolation and small size of the population threatens these individuals with stochastic events that may lead to further reduction in the population size. The Chitwan population of tiger, one of the largest remaining populations in the world, is also prone to this problem (Smith 1993). Due to these reasons, inbrecding in the tiger is probably going to be a serious problem. It is estimated that inbreeding is taking place in Chitwan at a level of $2 \%$ per generation (Smith and McDougal 1991).

\section{Status in Nepal}

In Nepal, the present range of the tiger is now confined to a few, small remnant forest sanctuaries. Of them, the Chitwan and Bardia National Parks (NPs), and Suklaphanta Wildlife Reserve (WR) can be classified as the zones of high tiger density. The Tarai forests from east to west are low density zones of tiger in Nepal (Yonzon 1981-82). Its exact number is yet unknown. Except in Chitwan, there are no programmes to monitor tiger density and movement patterns. Smith and Mishra (1981) have estimated over 60-100 tigers in Chitwan. The park officials have estimated about 50-75 tigers now in the district of Kanchanpur including Suklaphanta Wildlife Reserve. Warden (Pers. Comm.) has estimated more than 100 tigers in Banke and Dhangarhi districts including Bardia National Park (Mishra et al.1987). The tiger census of $1995-96$ has estimated the population to be $48-49$ in Chitwan, 3032 in Bardia, and $15-16$ breeding animals in Suklaphanta (DNPWC 1999).

\section{Territorial behaviour}

Animals of both sexes remain within their natal area until the new litter is approximately two months old. Thereafter, the sub-adult litter males disperse. Typically, mothers shift their territory so that a daughter acquires a portion of the mother's range (Sunquist 1981). Often there is still some territory overlap when the first litter of the daughter is born, but by the time the offspring of the daughter are approximately one year old there is very little overlap (Smith 1984). The overlap between adjacent ranges of females are recorded to be $7.1 \%$ in Chitwan. By the time daughters were established breeders the amount of overlap in their respective ranges was only $3.7 \%$. Female territories are, on an average, $38 \%$ the size of male territories. The territories range from 19 to $151 \mathrm{sq} \mathrm{km}$ (Average = 54.4, $\mathrm{SD}=35.8$ ) and female territories range from 10 to $51 \mathrm{sq} \mathrm{km}$ (Average $=20.7, \mathrm{SD}=9.2$ ) (Smith et al.1987a).

Territorial behavior of males is the most pronounced when females are in estrus. All tigers strive to occupy area with high prey densities. Urine, anal secretion, feces, and visual marks are used to delineate territory boundaries. Young female mark extensively when they begin to establish breeding ranges. Females mark in response to adjacent females (Smith 1984).

\footnotetext{
'Lecturer, Institure of Forestry, Pokhara
} 


\section{Reproduction}

According to Smith and McDougal (1991), the mean age of first reproduction for female was 3.4 years in Royal Chitwan NP, Nepal. The minimum period between successive birth ranged between 20-24 months (Average $=21.6, \mathrm{~N}=7$ ). The average reproductive life span of females was 6.1 years $(\mathrm{N}=$ $13, S D=10.4)$. The mean litter size for 49 litters was 2.98 (Range $=2-5$ ). Litters were born in all months except February. Birthing peak is from May to July and with a minor one in December. Sexual maturity in males was reached later than in females (Average $=4.8$ years) and ranged from 3.4 to 6.8 years. The average reproductive life was 2.8 years, ranging from 7 months to 6.3 years. The range of resident males encompassed from two to seven females. Breeding territories were established by direct takeovers and expanded generally by fights with adjacent males (Smith and McDougal 1991).

\section{Causes of inbreeding and inbreeding depression}

A male's genes will not spread through the population as rapidly as they would if males mated with a random sample of females from the population. The genetic structure of the Chitwan population therefore reduces the effective population size and increases the potential for inbreeding depression (Smith and McDougal 1991).

Due to the fragmentation of the pre-existing habitat, the tiger population is confined to restricted areas in Chitwan, Bardia and Suklaphanta. The gene flow is completely cut off between these populations of different habitats. This situation will probably increase the chances of related individuals' mating. Immigration of at least one individual per generation is required to maintain a viable population.

Because of the degrading quality of habitat along with poisoning and poaching, etc. (DNPWC 1999, and Esmond 1992), the population have tended to decrease. As the total population declines the effective population size will also tend to decrease and the chance of mating between related individuals will necessarily increase, resulting in inbreeding depression. If the gene flow cannot be maintained within a isolated population when the population is below the effective population level, it is obvious that heterozygosity and genetic variability will decrease.

The causes of extinction fall into two categories: systematic and stochastic factors. Systematic factors exert steady pressure on a population. Loss of habitat, for example, causes continual fragmentation of large mammal population into smaller and smaller population units, increasing the probability of inbreeding. So, efforts should be made to keep the population always well above the minimum viable population (MVP) size.

In a small population, normal variation in social structure, reproduction, sex ratio, and survival can lead to a situation in which the population size declines due to chance alone. For example, the birth of a series of litters composed predominantly of males which may ultimately result in a skewed sex ratio and drop in fecundity. In Chitwan the chance death of a large male tiger led to a drop in mean reproduction in the park for a period of three years following his death. It also caused competition by several adult males for female in the former territory and the subsequent infanticide of existing litters, resulted in a decline from a mean 2.6 to 1.1 subadults that survived to dispersal age (Smith et at 1987b). The environmental stochastic factors, for example, due to the fluctuations in habitat quality, weather, food, can affect the size of local population producing a decline to a lower level, and resulting in inbreeding.

The number of dispersal-aged offspring that females reproduced ranged from 0 to 12 . The mean and variance in lifetime reproduction were 4.54 and 11.48. Lifetime reproductive success (LRS) for males that established territories ranged from 0 to 27 cubs. Mean and variance in male LRS were 5.83 and 49.97 (Smith and McDougal 1991). Variance in individual LRS is a major component of both demographic and genetic stochasticity and is critical information for population vulnerability analysis (PVA) and effective population size ( $\mathrm{Ne}$ ).

Polygyny is the most common mating pattern in mammals and is a major factor contributing to LRS. In Chitwan a male tiger was able to maintain exclusive access to seven females for a period of four years and fathered 27 offspring that survived to dispersal age. Two other resident were displaced within less than one year by other males and produced no surviving offspring (Smith and McDougal 1991). In a study conducted by Smith and McDougal (1991), the estimated number of brecding tigers in the Chitwan population was 45 females and 20 males. Using the data on breeding sex-ratio and mean and variance of LRS Ne was estimated to be 26 . Which is much lower than 50 , required by MVP size.

\section{Efforts for improvement}

In 1973, The Smithsonian Institution (SM) of US provided technical and financial assistance to undertake long-term ecological research on the tiger, 
its prey and habitat requirements in Nepal, and established a Nepal Tiger Ecological Project. With funds from SM and the World Wildlife Fund the Chitwan NP area was expanded from 544 sq. $\mathrm{km}$ to 1,040 sq. $\mathrm{km}$. Knowledge of the dispersal and movement pattern of tiger, and management recommendations by the field biologists resulted in the creation of the new Parsa wildlife Reserve (545 sqkm), in 1985, which adjoins the Chitwan NP. His Majesty's Government of Nepal has approved the plan to manage the entire area of continuous forest as a tiger reserve system in which the Chitwan NP is the primary component or the core area (Smith and Mishra 1981). Bara forest (540 sq km) is under consideration for multiple use management as a fuelwood and/or hunting reserve (Smith et al 1987b). Besides Chitwan, two other reserves were established in Nepal by 1975; the Suklaphanta WR an d Bardia WR (Mishra et al.1987). The joint effort of India and Nepal over the past 12 years of Project Tiger have succeeded, at least temporarily, in halting the declining tiger numbers.

As an attempt to mitigate the conflict with the local people Department of National Parks and Wildlife Conservation (DNPWC) has formed user groups and buffer zone councils in Royal Chitwan National Park (RCNP) and Royal Bardia National Park under the Buffer Zone Management Regulation 2053. This recent regulation has made a provision to plough back $30-50 \%$ of the park revenue earning for the local development through user group (DNPWC 1999).

\section{Further potential of improvement}

Inbreeding of tiger in Chitwan is $2 \%$ per generation (Smith 1993). Franklin (1980), Soule (1980), and Frankel and Soule (1981) have recommended that there should be no more than $1 \%$ inbreeding per generation to avoid reduced fertility, decreased resistance to disease, and high juvenile mortality. Based on this estimate, the population probably should not drop below an effective population size of 50 (Smith et al 1987b). But fifty breeders is not offered as the critical threshold for all species; it is simply a reasonable guideline. Some species persist successfully at less than 50 , while others show deleterious effects well above 50 (Soule 1980). In the case of tigers in the wild, information to calculate the specific inbreeding threshold does not exist. So, more research is needed (Smith et al 1987b).

Minimum viable population (MVP) size is needed to ensure survival of a species population for a given length of time (Soule 1980, Franklin 1980, Frankel and Soule 1981). These authors articulated the concept of MVP when they postulated the 50/500 rule as a management goal to confront the problems of inbreeding depression and loss of genetic variability. Fifty for short term and 500 for long term viability.

PVA is based on three interacting fields. First is population phenotype (PP), which includes all the physical, chemical, and biological manifestations of the population. A second field, the environment $(E)$, includes all aspects of abiotic and biotic factors that influence the population. The third is the population structure and fitness (PSF). In this field the dynamic consequences of the interactions of $\mathrm{PP}$ and $\mathrm{E}$ are manifested (Gilpin and Soule 1986). PVA was developed to examine how stochastic factors interact to influence the persistence of small population (Gilpin and Soule 1986). Given the small size of existing population PVA modeling is needed to estimate the probability of extinction for each population and to evaluate the long term effectiveness of present management strategy (Smith and McDougal 1991). PVA using simulation modeling is an important tool to examine the genetic and demographic dynamics of population. For example, estimates of variance and co-variance of lifetime reproduction are needed to estimate $\mathrm{Ne}$, modeling can be used to complete these data sets. Stochastic modeling is a means of integrating genetic, demographic, and environmental parameters to examine the probability of population persistence under a given ecological and management regime. The success of PVA will depend on frequent interactions between modelers and field biologists who provide data to validate models generated from this approach (Smith and McDougal 1991).

There exist the critical factors of population size and population structure, below which inbreeding and loss of genetic variation become a problem for the continual survival of the population. Estimating MVP is complex because each situation will have a set of minima, depending on the life history of the species, the temporal and spatial distribution of its resource, and its level of genetic variation (Gilpin and Soule 1986). An attempt should be made to find the probable MVP and apply to the Bengal tiger as an attempt to improve the situation.

To derect inbreeding depression, either different populations can be compared or the same population can be monitored over a considerable period of time. The difficulty with comparison among population is that environmental conditions co-vary with genetic change. Detection of inbreeding depression is a problem faced by conservation biologists. There are too few long-term field studies done and those that are done rarely 
duplicate. If they are repeated, several variables often vary between studies (Smith and McDougal 1991).

If habitat fragmentation results in the complete genetic isolation of habitat islands, then each "island" becomes demographically independent and local extinction can occur. When there is no opportunity for recolonization, each local extinction brings the global population irreversibly one step closer to total extinction. It is therefore, critical to know if habitat fragmentation actually prevents dispersal or not. The most severe genetic consequences from habitat fragmentation, such as a drastic loss of genetic variability within habitat islands and inbreeding depression may result (Templeton et al 1990).

Restricted habitat is one of the important factors for making the tiger vulnerable. Efforts are being made to extend the area adjoining to Chitwan. The area extension of Bardia NP and Suklaphanta WR will also be helpful to provide more room for the tiger as far as possible. Other forest areas adjoining to the NPs and WRs should be developed into buffer zones, and the parks and reserves will be treated as core areas.

The core area should have no disturbance for wildlife whereas the buffer areas should be managed for the benefit of both the wildlife as well as the rural communities. In this way the habitat range of wildlife will increase in one hand and the conflict between people and wildlife will decrease in the other hand. The close habitats should be connected with the creation of corridors, such as Bardia and Suklaphanta. These habitats can also be connected with the tiger habitat in India, in the southern frontier.

Corridors and connectivity between protected areas - within the country, as well as between Nepal and India are essential to allow for the safe dispersal of the tiger (DNPWC 1999). Trans boundary meeting, between India and Nepal is essential for the conservation of natural resources at the landscape level (Adhikari 1999). Creation of corridors will facilitate the free movement of individuals between different habitats, resulting in an adequate amount of dispersion and gene flow. This will ultimately improve the genetic variability and reduce the chance inbreeding (Hobbs 1992). For the habitat areas where there is no way to make corridors in such area exchange of individuals between different habitats should be done. In the Nepalese context exchange between Chitwan and Bardia or Suklaphanta population can be done.
There should be adequate amount of supervision and monitoring for the information about dispersal, and close relatives should be avoided from the proximity. Wider dispersal of close relative will minimize the probability of inbreeding, especially at the time of mating.

Catastrophic stochastic factors, such as flood, firc, hurricane, can cause sudden drastic declines and extinction in a local population. So, populations in different habitats like Chitwan, Bardia, and Suklaphanta should be maintained, which can replenish the population in such situation.

\section{Conclusion}

Some amount of inbreeding in tiger is likely to take place in Nepal, but quantification of its level has been very difficult for the lack of adequate data. Some research has been done in Chitwan NP through tiger project. Information about other NPs, WRs and forest areas containing tigers is unknown, except for rough estimates of the population size. It is prudent to have a genetic assay to determine the inbreeding coefficient and find out the level of inbreeding in the existing population. This will help to develop a well defined strategy in the protection of tiger, well before the crisis.

The insular tiger habitats should be connected to cach other either by creating corridors or by the exchange of individuals between different habitats, and genetic diversity should be maintained at a safer level. The effective population should be maintained by improving the fecundity of the existing population, combined with the improvement of the habitat quality by improving the predator-prey balance. Population viability analysis is essential to know the viable population size and effective population size. Care should also be given to keep the proper age and sex ratio in the area. Thus, the population must be maintained well above the MVP level. In addition, people participation and conservation education for the awareness of the people is also crucial in this program to make it effective and sustainable in the days to come. The buffer zone concept is anticipated to be helpful in achieving people's participation. Without the participation of people it is hard to obtain the desired goal of real conservation of the endangered large mammals like the tiger.

\section{References}

Adhikari, T. R. 1999. The status of the tiger (Panthera tigris). The Nepal Journal of Forestry 11(1):13-20. 
Brade, W. and W. Strube. 1991. Inbreeding depression and influence of inbreeding on genetic variability. Arcbiv Fuer Gefluegelkunde 55(2): 74-78.

DNPWC. 1999. Tiger Conservation Action Plan for the kingdom of Nepal. Ministry of Forests and Soil Conservation, Department of National Parks and Wildlife Conservation, Kathmandu, Nepal.

Esmond, B.M. 1992. The poisoning of rhinos and tigers in Nepal. Oryx 26(2): 82-86.

Frankel, O.IH. and M.E. Soule. 1981. Conservation and evolution. Cambridge University press, Cambridge, U.K.

Franklin, I.R. 1980. Evolutionary change in small populations. Pages 135-150 in M.E.Soule and B.A.' Wilcox (Eds.). Conservation Biology: An evolutionary-ecological perspective. Sinauer, Sunderland, MA.

Gilpin, M.E. and M.E. Soule. 1986. Minimum viable population: Process of species extinction. Pages 19-34 in Soule, M.E. (Eds.). Conservation Biology: The science of scarcity and diversity.

Hobbs, R.J. 1992. The role of corridors in conservation. Solution or bandwagon? Tree 7(11): 389-392.

Holloway, C. W., P. Leyhausen, and M.K. Ranjitsingh. 1976. Conservation of the tiger (Panthera tigris tigtis) in India. WWF Report. Gland, Switzerland.

Mishra, H. R, C. Wemmer, and J.L.D. Smith. 1987. Tigers in Nepal: Management conflicts with human interests. Pages 449-463 in Tilson, R.L. and U.S. Seal (Eds.). Tigers of the world: The biology, biopolitics, management, and conservation of an endangered species.

Ralls, K. , P.H. Harvey, and A.M. Lyles. 1986. Inbreeding in natural populations of birds and mammals. Pages 35-56 in Soule, M.E. (Eds.). Conservation Biology: The science of scarcity and diversity.

Schafer, Kelvin and Martin Hill. 1993. The logger and the tiger. Wildlife Conservation 96(3): 2330.

Schaller, George B. 1984. The deer and the tiger: a study of wildlife in India. The University of Chicago Press, Chicago and London $370 \mathrm{Pp}$.
Smith, J.L.D. 1993. The role of dispersal in structuring the Chitwan tiger population Behavior 124(3-4):165-195.

Smith, J.L.D. and Charles McDougal. 1991. The contribution of variance in life time reproduction to effective population size in tigers. Conservation Biology 5(4): 484-490.

Smith, J.L.D. et al. 1987a. Female land tenure system in tigers. Pages 97-109 in Tilson. R.L. and U.S. Seal (Eds.). Tigers of the world: The biology, biopolitics, management, and conservation of an endangered species.

Smith, J. L. D., C. Wemmer, and H.R. Mishra. 1987b. A tiger geographical information system: The first step in global conservation strategy. Pages 464-474 in Tilson, R.L. and U.S. Seal (Eds.). Tigers of the world: The biology, biopolitics, management, and conservation of an endangered species.

Smith, J.D.L. 1984. Dispersal, communications, and conservation strategies for the tiger (Panthera tigris) in Royal Chitwan National Park, Nepal. Ph.D. thesis, Univ. Minnesota, St. paul.

Smith, J.D.L., and H.R. Mishra. 1981. Management recommendations for the Chitwan tiger population. The Parsa - extension and the Bara Hunting Reserve. Smithson. Inst./WWF Project 1051.

Soule, M.E. 1980. Thresholds for survival: maintaining fitness and evolutionary potential in Soule, M.E. and B.A. Wilcox. (Eds.). Conservation Biology, Sunderland, Mass.: Sinauer Assoc.

Sunquist, M.E. 1981. The social organization of tigers (Pantbera tigris) in Royal Chitawan National Park. Smithson. Contrib. Zool. No. 336.

Templeton, A.R et al. 1990. The genetic consequences of habitat fragmentation. Annals of the Missouri Botanical Garden 77(1):13-27.

Yonzon, Pralad B. 1981-82. Tiger (Panthera tigris) pages $400-407$ in Wild is Beautiful: Introduction to the magnificent, rich and varied fauna and wildlife of Nepal. Ed. Majupuria. Lalitpur colony, Lashkar (Gwalior), India. 